\title{
Junior High Students' Critical Thinking in Geometry Problem Solving
}

\author{
Haerul Syam ${ }^{1,2, *}$, Akbar Sutawidjaja ${ }^{3}$, Cholis Sa'dijah ${ }^{3}$, Abadyo $^{3}$ \\ ${ }^{1}$ Postgraduate Program in Mathematics Education, Universitas Negeri Malang, Indonesia \\ ${ }^{2}$ Department of Mathematics, Faculty of Teacher Training and Educational Sciences, Universitas Muhammadiyah Makassar, \\ Indonesia \\ ${ }^{3}$ Department of Mathematics, Faculty of Mathematics and Natural Science, Universitas Negeri Malang, Indonesia
}

Received July 22, 2020; Revised September 30, 2020; Accepted October 19, 2020

\section{Cite This Paper in the following Citation Styles}

(a): [1] Haerul Syam, Akbar Sutawidjaja, Cholis Sa'dijah, Abadyo, "Junior High Students' Critical Thinking in Geometry Problem Solving," Universal Journal of Educational Research, Vol. 8, No. 11B, pp. 5880 - 5887, 2020. DOI: 10.13189/ujer.2020.082221.

(b): Haerul Syam, Akbar Sutawidjaja, Cholis Sa'dijah, Abadyo (2020). Junior High Students' Critical Thinking in Geometry Problem Solving. Universal Journal of Educational Research, 8(11B), 5880 - 5887. DOI: 10.13189/ujer.2020.082221.

Copyright $\mathrm{C} 2020$ by authors, all rights reserved. Authors agree that this article remains permanently open access under the terms of the Creative Commons Attribution License 4.0 International License

\begin{abstract}
In this study, students' critical thinking in geometry problem solving is referred to the five stages namely Identifying, Visualizing, Analyzing, Applying and Evaluating. Some aspects were evaluated at every stage. Identifying included elaborating information, associating problems with prior knowledge and stating the root of the problem; Visualizing included using images or sketches to represent the problem; Analyzing encompassed simplifying problem situations and making an initial prediction or conjecture; Applying involved determining the stages for solving the problem and finding the solution to the problem; and Evaluating included clarifying the key terms used and rechecking the problem-solving result. This qualitative study was conducted on 60 students from SMP Negeri 1 Pangkajene. The data were collected using a geometry problem-solving test. The results of the analysis showed that at the Visualizing stage, three subjects used a garden drawing or sketched a garden to represent the problem, while one subject solved the problem without representation. At the Applying stage, all of the subjects used different strategies to solve the geometry problem.
\end{abstract}

Keywords Process, Critical Thinking, Problem Solving

\section{Introduction}

Rapid science and technological advancements require human resources to be reliable and able to think critically, logically as well as communicate ideas effectively $[1,2]$. Critical thinking skills in mathematics is closely related with problem solving in mathematics [3]. Higher order thinking skills, such as critical thinking and problem-solving skills, are important for individuals to live in the $21^{\text {st }}$ century [4-6]. Critical thinking skills are needed in the development of students because they can influence the development of thinking [7]. Critical thinking is one's effort to collect, interpret, analyze and evaluate information to obtain a valid and reliable conclusion [8-10]. Critical thinking is ideally comprised of some criteria that are Focus, Reason, Inference, Situation, Clarity, and Overview, also known as FRISCO [11]. According to Facione [12], critical thinking consists of Interpretation, Analysis, Evaluation, Inference, Explanation, and Self-Regulation skills. This study examined students' critical thinking in geometry problem-solving through Identifying, Visualizing, Analyzing, Applying and Evaluating stages.

Critical thinking is a mental activity performed to build and acquire knowledge $[13,14]$. Students' critical thinking can be promoted by enriching their meaningful learning experience through problem-solving activity. Ennis [11] states that individuals with critical thinking ideally possess some criteria abbreviated as FRISCO (Focus, Reason, Inference, Situation, Clarity, and Overview). Focus is to understand a problem; Reason includes recognizing reasons that support or disprove decisions made based on relevant facts. Inference refers to the making of the right 
conclusion based on logical steps, Situation is to understand problem situations and maintain the situations in thinking in order to help clarify questions, Clarity includes explaining the key terms used either in written or oral opinions and Overview is to review and analyze the decision made thoroughly. According to Facione [12], critical thinking encompasses Interpretation, Analysis, Evaluation, Inference, Explanation, and Self-regulation skills. Interpretation refers to the ability to understand, explain, provide meaning or information; Analysis is the ability to identify relationships and information used in expressing thoughts or opinions; Evaluation involves the ability to test the truth from information obtained to express thoughts or opinions; Inference refers to the ability to draw a relevant conclusion; Explanation involves the ability to explain or state the results of a thinking process based on the available proof, methodology and contexts; and Self-regulation consists of the ability to convince self.

This study aimed to examine students' critical thinking in solving geometry problems. The results of a preliminary study showed that students began solving a geometry problem by describing the information, relating the problem to prior knowledge and stating the essence of the problem. This stage is defined by Ennis as focus, recognizing the main points, issues, questions or problems, while in Facione, it refers to Interpretation or the ability to understand, explain, provide meaning or information. However, in this study, the term Identifying was used. At the next stage, the students sketched a garden, which according to Pachemska \& Lazarova [15] reflects visualization in mathematics or the process of forming images (using a pencil and paper) which is effectively used to understand and find problems in mathematics. This study used the term Visualizing to describe the process. After visualization, the students simplified the problem situation and made an assumption. Ennis refers these activities as Reason or investigating reasons to support conclusion drawing and Situation or understanding the situation as well as recognizing the meaning of the term and the relevant parts as a support. Facione categorizes these processes into Analysis or the ability to identify relationships and information used to express thoughts or opinions. In this study, the term Analyzing was used to define these processes. Following the Analyzing stage, the students then defined the completion steps and found a solution, which in Ennis and Facione are referred to as Inference or drawing the correct and logical conclusions based on steps from reasons to inference. In this study, these activities were categorized into Applying. Finding the solution was followed by clarifying terms and examining the results. These activities are categorized by Ennis into Clarity criteria, that is to explain meaning or terms used to provide oral or written opinions and Overview that is to review and thoroughly examine the decisions made. Facione defines the ability to test the correctness of the information used to express thoughts or opinions as Evaluation and describes
Explanation as the ability to explain or state ideas based on evidence, methodology and context, while Self regulation refers to the ability to convince self. In this study, this was referred to as Evaluating.

Based on the supporting theory and the results of the preliminary studies on critical thinking, this study aimed to analyze students' critical thinking in geometry problem-solving through Identifying, Visualizing, Analyzing, Applying and Evaluating stages. Some aspects were evaluated at every stage. Identifying included elaborating information, associating problems with prior knowledge and stating the root of the problem [16-18], Visualizing included using images or sketches to represent the problem [13,19,20], Analyzing encompassed simplifying problem situations and making an initial prediction or assumption; Applying involved determining the stages for solving the problem and finding the solution; and Evaluating included clarifying the key terms used and rechecking the problem-solving result.

\section{Methods}

This study used a descriptive qualitative approach to explaining students' critical thinking in solving geometry problems. The subjects of this study consisted of the eight graders from SMP Negeri I Pangkajene Kabupaten Pangkajene. The subjects were not randomly selected, but chosen based on their initial knowledge of geometry. This was done to support the process of examining the students' problem-solving process. Prior to selecting the subjects, a geometry test was administered to the students. Students who were able to solve the basic geometry problem were categorized as the prospective subjects. The prospective subjects were asked to solve mathematical problems on geometry by voicing what was on their mind, so their critical thinking process in solving the problems could be examined. The results of the test and the recording transcriptions were described based on the following stages; Identifying, Visualizing, Analyzing, Applying and Evaluating until saturation was achieved. According to Sugiyono [21], data saturation is reached when new information no longer exists to support the previously obtained information. The test had undergone expert validation before it was administered to the subjects for data collection. Both validators have expertise in mathematics and come from Universitas Negeri Malang. Test validity examined in this study was content validity to test whether the content of the test had fulfilled the requirements for test materials, construction and language.

The instruments used in this study were the researcher, a problem-solving test, and interview guidelines. A handycam was used to record the participants' thinking process while doing the problem-solving test. The geometry problem-solving test used in this study was presented as follows. 


\section{Geometry Problem-solving Test Question}

The side lengths of a triangle shaped garden are $6 \mathrm{~m}, 8 \mathrm{~m}$ and $10 \mathrm{~m}$, respectively. Ali is going to plant a square area inside the garden with grass. What is the largest square area that can be planted by Ali?

\section{Result and Discussion}

The participants' critical thinking process in geometry problem-solving was evaluated at five stages: Identifying, Visualizing, Analyzing, Applying, and Evaluating. The Identifying stage consisted of elaborating information of the problem, associating the problem with prior knowledge and stating the root of the problem. The Visualizing stage involved using pictures or sketches to represent the problem; Analyzing was comprised of simplifying the problem situation and making an initial prediction or assumption. Applying consisted of determining the stages for solving the problem and finding the solution and at the Evaluating stage, the key words used in the problem-solving activity were clarified and the problem-solving result was rechecked. Based on the problem-solving result, each of the subjects performed different activities at the Applying stage where they needed to determine the steps to solve the problem and find the solution.

\section{Subject 1 (FD)}

The geometry problem-solving result by Subject 1 can be seen in Figure 1.

Figure 1 showed that subject 1's critical thinking process in solving the geometry problem started from acquiring information about the side lengths of a triangle shaped garden which were $6 \mathrm{~m}, 8 \mathrm{~m}$ and $10 \mathrm{~m}$ and about Ali who was going to plant a square area inside the garden with grass. Then, Subject 1 associated the information with his prior knowledge of right triangles and the Pythagorean theorem and concluded that the triangle was a right triangle (Identifying). This was shown by the results of the interview conducted with Subject 1 ( $P$ is the researcher and $\mathrm{S} 1$ is subject 1).

P: How did you know that the triangle was a right triangle?

S1: Because the side lengths are $6 \mathrm{~m}, 8 \mathrm{~m}$ and $10 \mathrm{~m}$. The numbers fulfill the the Pythagorean theorem's requirement, so I concluded that the triangle is a right triangle.

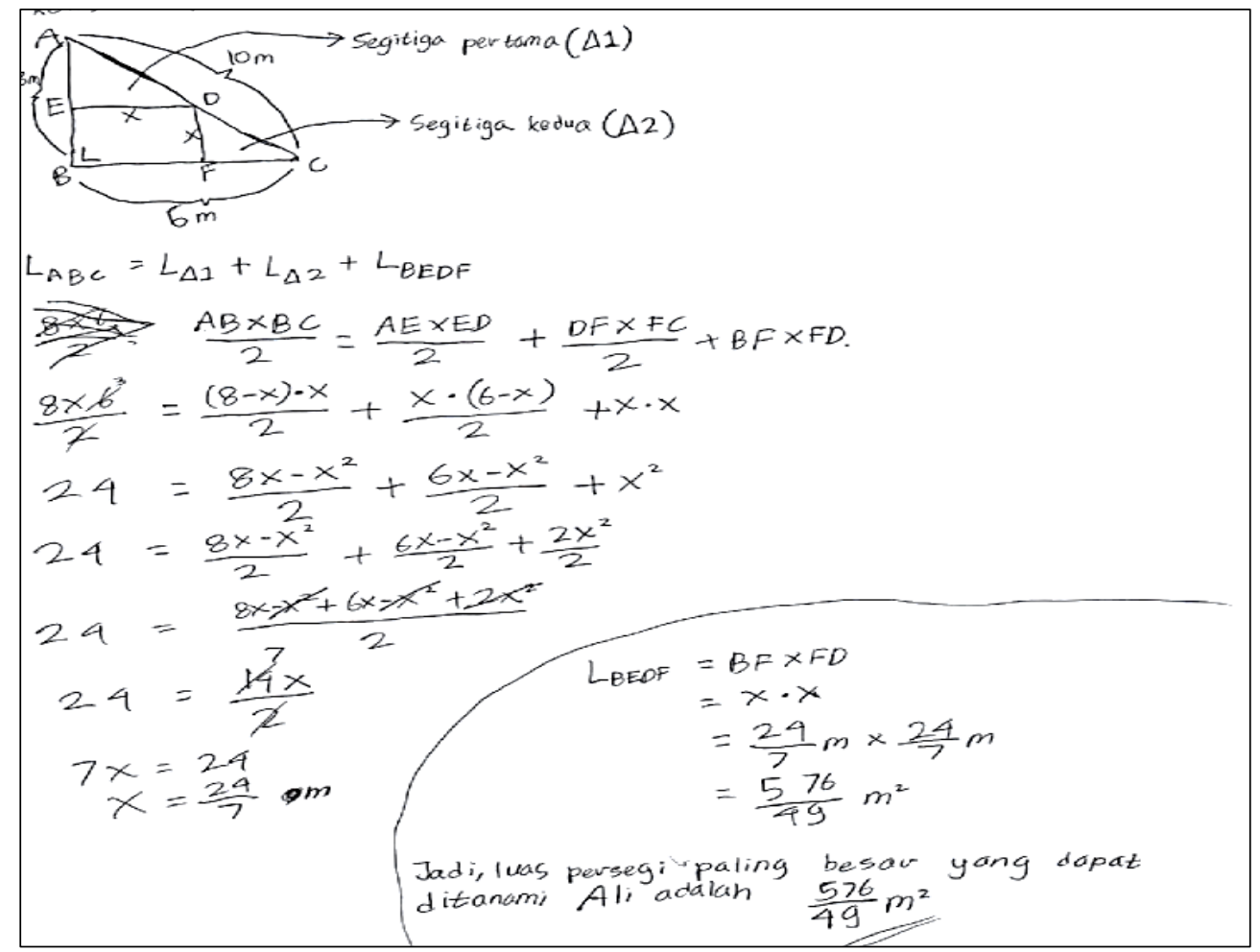

Figure 1. The Geometry Problem-Solving Result by Subject 1 
After investigating the root of the problem, S1 drew a sketch of a triangle shaped garden with a square inside (Visualizing). Then, S1 made an assumption that the problem could be solved using a big triangle approach of which measurements were identified in the question (Analyzing). Subject 1 decided to use a right triangle approach (the $\mathrm{ABC}$ triangle) to solve the problem. This was indicated in the following excerpt.

P: What strategy did you use to solve this problem?

S1: I used the $\mathrm{ABC}$ triangle approach. The area of triangle $\mathrm{ABC}$ is the same as the sum of the first triangle area, second triangle area, and square area.

The $\mathrm{ABC}$ triangle approach meant here was to figure out that the $\mathrm{ABC}$ triangle area equals the sum of three areas inside it, that of the BEDF square, the AED $(\Delta 1)$ triangle and the DFC $(\Delta 2)$ triangle. Subject 1 then continued substituting values on the $\mathrm{ABC}, \Delta 1, \Delta 2$ triangles and the $\mathrm{BEDF}$ square. The area of the $\mathrm{ABC}$ triangle $=\frac{6 \times 8}{2}$, the area of the AED triangle $=\frac{8 x-x^{2}}{2}$, the area of the DFC triangle $=\frac{6 x-x^{2}}{2}$ and the area of the BEDF square $=x^{2}$. Through this process, $\mathrm{S} 1$ was able to determine the value of $\mathrm{x}$. Subject then calculated the greatest area of the square using the area formula. S1 discovered the solution and figured out that the greatest area of the square was $=\frac{576}{49}$ $\mathrm{m}^{2}$ (Applying). After finding the solution, Subject 1 explained the terms used in the process, rechecked the answer obtained from applying the square area formula, determined the value of $\mathrm{x}$ and the multiplication result (Evaluating).

\section{Subject 2 (AY)}

The geometry problem-solving result by Subject 2 can be seen in Figure 2.

Based on the result of the geometry problem-solving test presented in Figure 2, it was known that Subject 2's critical thinking process was initiated by reading activity. Subject 2 read the question a few times while pointing at the picture. After reading the question, Subject 2 acquired information that the garden was a triangle with the side lengths of $6 \mathrm{~m}, 8 \mathrm{~m}$ and $10 \mathrm{~m}$, respectively. Subject 2 also figured out that Ali was going to plant a square inside the garden with grass and that he was going to find out the greatest square area that can be planted by Ali. S2 associated this information with his prior knowledge of right triangles (Identifying). This was indicated in the excerpt of the interview conducted with Subject 2.

P: After you acquired the information, how did you figure out that the triangle is a right triangle?

S2: The lengths of the sides are $6 \mathrm{~m}, 8 \mathrm{~m}$ and $10 \mathrm{~m}$, showing the measurement of a special triangle, including a right triangle.

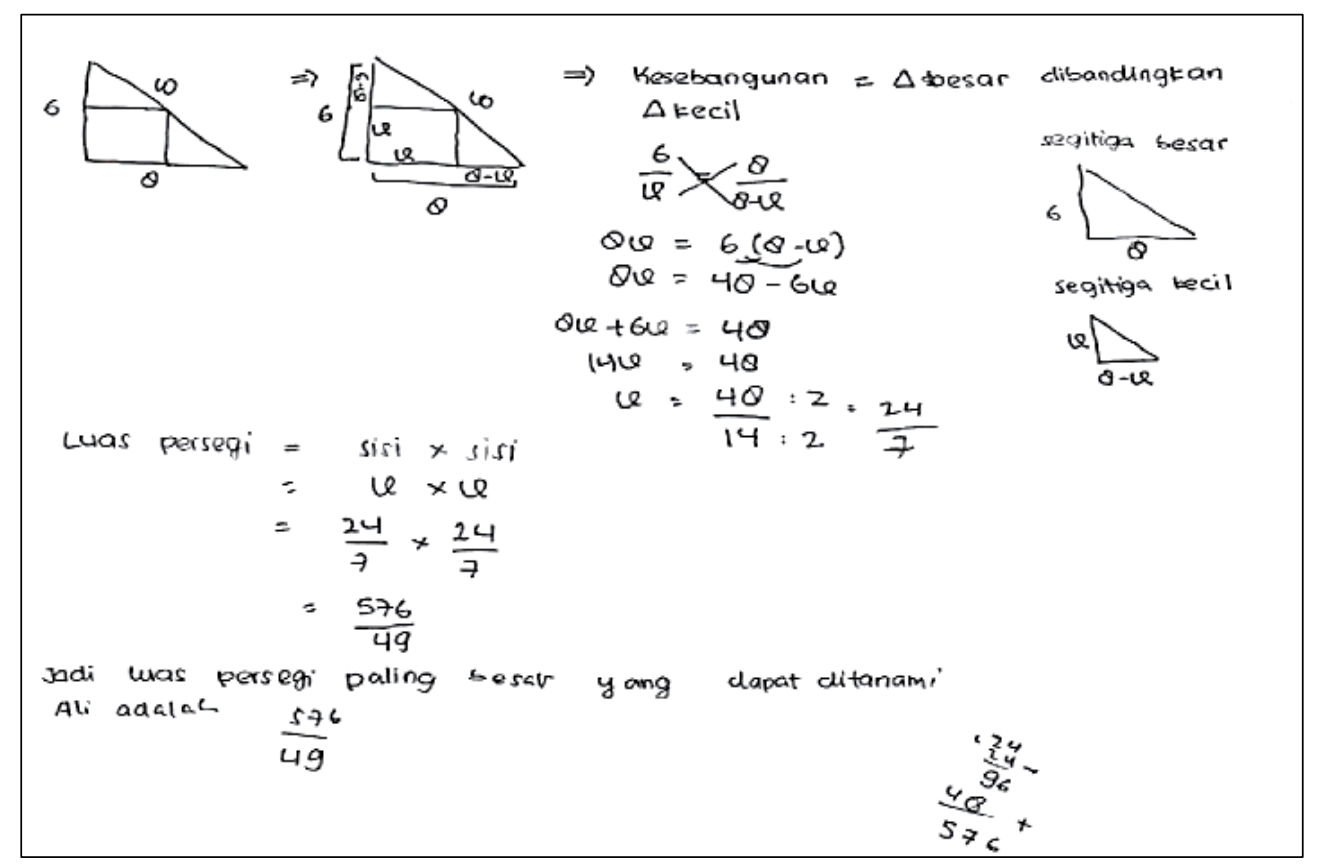

Figure 2. The Geometry Problem-Solving Result by Subject 2 
Based on the information, S2 sketched a triangle-shaped garden with a square inside it (Visualyzing). To figure out the area of the square, S2 had to find out each of the side's length. After looking at the sketch, S2 assumed that the problem could be solved with congruence theory that is to compare the corresponding sides (Analyzing). This was shown in the following interview excerpt.

P: What strategy did you use to solve this problem?

S2: So, the strategy I used was congruence.

$\mathrm{P}$ : What is congruence strategy?

S2: Since there are some triangles here, I used the congruence theory that is to compare the corresponding sides.

P: What did you compare?

S2: I compared the big triangle with a height of six meters and a base of eight meters to the smaller triangle which has a height of $\mathrm{x}$ and a base of eight $\mathrm{x}$.

S2 solved the problem using congruence strategy by comparing the big triangle to the small triangle. The base and height of the big triangle are $8 \mathrm{~m}$ and $6 \mathrm{~m}$, respectively, while the small triangle is the triangle inside the right triangle with a base of $8-x$ and a height of $x$. The result of the triangles comparison was $\frac{6}{x}=\frac{8}{8-x}$; hence $x=\frac{24}{7}$. After determining the value of $\mathrm{x}, \mathrm{S} 2$ calculated the greatest square area using the $\mathrm{s}^{2}$ formula and found that the largest square area that can be planted by Ali $=\frac{576}{49} \mathrm{~m}^{2}$ (Applying). The final problem-solving activity was followed by S2 explaining the terms used, rechecking the result of comparing the corresponding sides, determining the value of $\mathrm{x}$ and the multiplication result (Evaluating).

\section{Subject 3 (AM)}

The geometry problem-solving result by Subject 3 can be seen in Figure 3.

$\begin{aligned} \frac{8}{u} & =\frac{6}{6-u} \\ 48-8 u & =6 u \\ 48 & =8 u+6 u \\ 48 & =14 u \\ \frac{48}{14} & =u \\ \frac{24}{7} & =u \\ \angle \square & =\frac{24}{7} \cdot \frac{24}{7} \\ & =\frac{576}{49}\end{aligned}$

Figure 3. The Geometry Problem-Solving Result by Subject 3

Based on Figure 3, it was concluded that Subject 3's critical thinking process began with reading the question repeatedly to obtain information that there was a triangle shaped garden with the side lengths of $6 \mathrm{~m}, 8 \mathrm{~m}$ and $10 \mathrm{~m}$, respectively. Subject 2 also figured out that Ali was going to plant a square inside the garden with grass and that he was going to find out the greatest square area that can be planted by Ali. Based on the information, S3 made a link between the numbers presented in the question and his prior knowledge of special sides of a triangle. Thus, S3 came to a conclusion that the triangle was a right triangle (Identifying). This was shown in the following excerpt of interview conducted to Subject 3.

P: After reading the question, what information did you acquire?

S3: There was a triangle shaped garden with the side lengths of $6 \mathrm{~m}, 8 \mathrm{~m}$ and $10 \mathrm{~m}$, respectively. It is a right triangle. Ali is going to plant a square area inside the triangle. Find the largest square area that can be planted by Ali.

After discovering the root of the problem, Subject 3 visualized a right triangle with a square inside and a triangle on top of the square (Visualizing). To find out the area of the triangle, S3 had to figure out the length of the side. S3 assumed that this problem can be solved by comparing the corresponding sides (Analyzing). This was indicated by the result of the interview conducted by the researcher to Subject 3.

P: What strategy did you use?

S3: Comparison

P: What did you compare?

S3: I compared the big triangle to the small triangle. .8 is the base length of the big triangle $x$ is the base length of the small triangle, the height length of the big triangle is 6 and the height length of the small triangle is $6-\mathrm{x}$.

Subject determined that the problem could be solved by making a comparison between the big triangle and the small triangle. The big triangle has a base of $8 \mathrm{~m}$, a height of $6 \mathrm{~m}$, and a hypotenuse of $10 \mathrm{~m}$, while the small triangle on top of the square has a base of $\mathrm{x}$ and a length of $6-\mathrm{x}$. To investigate the length of the square side, comparison strategy was used. The comparison between the base and the height of the triangle could be written as $\frac{8}{x}=\frac{6}{6-x}$; hence $\mathrm{x}=\frac{24}{7}$. After the value $\mathrm{x}$ was determined, $\mathrm{S} 3$ the calculated the area of the largest square possible for Ali using the square area formula or $\mathrm{s}^{2}$. As a result, the area of the largest area could be written as $\frac{576}{49} \mathrm{~m}^{2}$ (Applying). The final stage of the problem-solving activity consisted of explaining the terms used, rechecking the answer obtained by comparing the corresponding sides and determining the value of $\mathrm{x}$ and the multiplication result (Evaluating).

\section{Subject 4 (MS)}

The geometry problem-solving result by Subject 4 can be seen in Figure 4. 

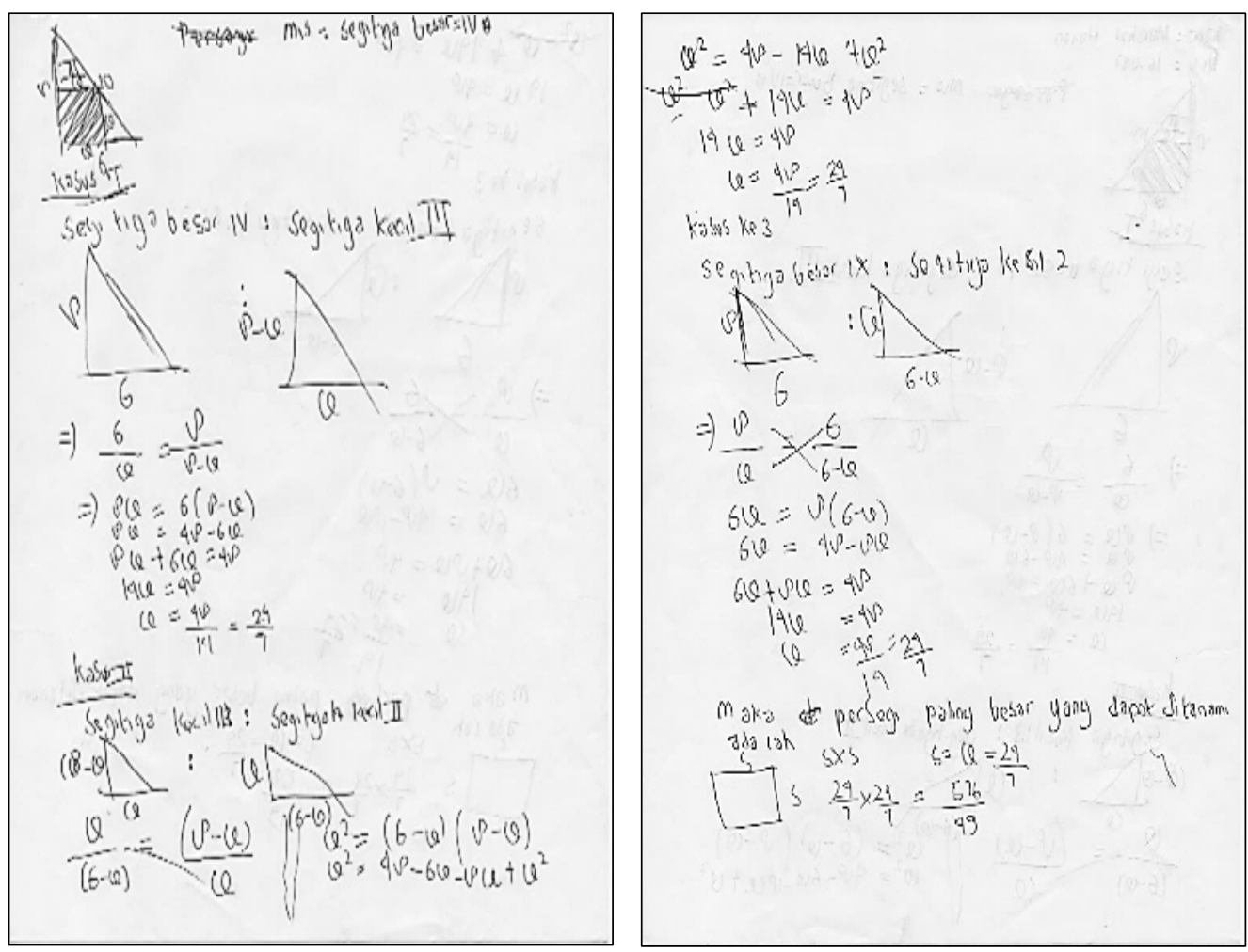

Figure 4. The Geometry Problem-Solving Result by Subject 4

Figure 4 showed that Subject 4's critical thinking process in solving the geometry problem began with reading while pointing at the question. After reading the question, Subject 4 acquired information that there was a triangle shaped garden with the side lengths of $6 \mathrm{~m}, 8 \mathrm{~m}$ and $10 \mathrm{~m}$, respectively. Subject 4 also figured out that Ali was going to plant a square inside the garden with grass and that he was asked to find out the greatest square area that can be planted by Ali (Identifying). This was shown in the following interview excerpt. (P for researcher, S4 for Subject 4)

P: After reading the question, what information did you obtain?

S4: There was a triangle shaped garden with the side lengths of $6 \mathrm{~m}, 8 \mathrm{~m}$ and $10 \mathrm{~m}$, respectively. It is a right triangle. Ali is going to plant a square area inside the triangle. I am asked to find the largest square area that can be planted by Ali.

Subject 4 made an attempt to visualize the problem by sketching a right triangle with a square inside. The bigger triangle was symbolized with roman numeral (IV), the smaller triangles were symbolized with roman numeral (II) and (III), and the square was symbolized with roman numeral (I) (Visualizing). Based on the picture, S4 was able to identify the situation used to solve the problem. He discovered that there was right triangle shaped garden with the side lengths of $6 \mathrm{~m}, 8 \mathrm{~m}$ and $10 \mathrm{~m}$, respectively. A square area inside the garden was going to be planted with grass. Subject 4 focused his attention on the sketch. On the sketch, there were three two-dimensional figures, two triangle and one square that have unknown side lengths. To figure out the area of the square, S4 had to find out the length of the side. According to the sketch, S4 assumed that the problem could be solved using three cases analysis (Analyzing). This was shown in the result of the interview conducted between the researcher and S4.

P: What strategy did you use to solve this problem?

S4: I used three cases comparison strategy. First, I considered the square the first figure, symbolized (I), next to the square is a small triangle, symbolized (II), and above the square there is another small triangle, symbolized (III)... and the big triangle is symbolized (IV)

To find the area of the largest square, S4 had to calculate the length of the side first using three cases comparison analysis. First was to compare the corresponding sides of the big triangle (IV) to the third small triangle (III) to obtain $\frac{6}{x}=\frac{8}{8-x}$; hence $x=\frac{24}{7}$. Second was to compare the corresponding sides of the third small triangle (III) to the second small triangle (II). The result was $\frac{x}{6-x}=\frac{8-x}{x}$; hence $x=\frac{24}{7}$. Third was to compare the corresponding sides of the big triangle (IV) to the second small triangle (II) to obtain $\frac{8}{x}=\frac{6}{6-x}$. As a result, $x=\frac{24}{7}$. After finding the value of $\mathrm{x}, \mathrm{S} 4$ continued with calculating the largest square area suing the square area formula $\mathrm{s}^{2}$, so that $\mathrm{S} 4$ was able to determine the garden area that can be planted with grass, $\frac{576}{49} \mathrm{~m}^{2}$ (Applying). Subject 4 then explained the terms used in the problem-solving process, reexamining the answer and determining the value of $\mathrm{x}$ from each of the cases and 
as well as finding the multiplication result (Evaluating).

\section{Conclusions}

The current study examined Junior High Students' critical thinking in geometry problem-solving. Based on the discussion and the results of the study, it can be concluded that: Junior High School students undergo five stages of critical thinking that are Identifying, Visualizing, Analyzing, Applying, and Evaluating. The students' critical thinking process begins with reading the question, obtaining information from the reading activity and associating the information with prior knowledge so that the root of the problem can be identified (Identifying). The identification of the problem is followed by visualization in the form of sketches drawing. The visualization appears based on the stimulation given by the question and is used to understand the problem at a more in-depth level (Visualizing). Based on the visualization result, the problem situation can be simplified and an assumption on how to solve the problem can be created (Analyzing). The analysis stage is followed by determining the strategy to solve the problem. It has been found that every student performs different problem-solving strategies. There were three strategies used by the students in this study: the triangle approach, congruence strategy and three-case comparison (by comparing the areas of three triangles). The difference in the students' strategy to solve the problem results from the difference in the students' ability to process information (working memory) and to visualize the sketch (Applying). After finding the solution to the problem, the students rechecked their answer and clarified the terms used in the problem-solving activity (Evaluating).

\section{Acknowledgments}

We are very grateful to experts for their appropriate and constructive suggestions to improve this research.

\section{REFERENCES}

[1] Florea, N. M., \& Hurjui, E. (2015). ScienceDirect Critical thinking in elementary school children. Procedia - Social and Behavioral Sciences, 180 (November 2014), 565-572. https://doi.org/10.1016/j.sbspro.2015.02.161.

[2] Zhu, Z. (2007). Gender differences in problem mathematical problem solving patterns: A review of Literature. International Education Journal, 8(2), 187-203.

[3] Firdaus, F., Kailani, I., Bakar, M. N. Bin, \& Bakry, B. (2015). Developing Critical Thinking Skills of Students in Mathematics Learning. Journal of Education and Learning
(EduLearn), 9(3), 226. https://doi.org/10.11591/edulearn.v9 i3. 1830 .

[4] Mason, Mark. (2008). "Critical Thinking and Learning". Philosophy of Education Society of Australasia34-339.

[5] Ahdhianto, E., Marsigit, Haryanto, \& Nurfauzi, Y. (2020). Improving fifth-grade students' mathematical problem-solving and critical thinking skills using problem-based learning. Universal Journal of Educational Research, 8(5), 2012-2021.https://doi.org/10.13189/ujer.20 20.080539

[6] Thomas Theda. (2011). Developing First Year Students' Critical Thinking Skills. Asian Social Science, Vol. 7, No. 4.

[7] Hikayat, C., Suparman, Hairun, Y., \& Suharna, H. (2020). Design of realistic mathematics education approach to improve critical thinking skills. Universal Journal of Educational Research, 8(6), 2232-2244.https://doi.org/10.1 3189/ujer.2020.080606

[8] Chukwuyenum, A, N. (2013). Impact of critical thinking on performance in mathematics among senior secondary school students in Lagos state. IOSR Journal of Research \& Method in Education, 3(5), 18-25.

[9] Peter, E. E. Critical thinking: Essence for teaching mathematics and mathematics problem solving skills. African Journal of Mathematics and Computer Science Research, 5(3), 39-43, 2012.

[10] Willingham, D. T. 2008. Critical thinking: Why is it so hard to teach? Arts Education Policy Review, 109, 21-32. doi:10.3200/AEPR.109.4.21-32.

[11] Ennis, R. H. Critical Thinking. United State of America: Prentice- Hall. 1996.

[12] Facione, P. A. (2011) Critical Thinking: What It Is and Why It Counts. Millbrae, CA: Measured Reasons and The California Academic Press.

[13] Chaffee. J. (2012). Thinking critically 10thed. Boston: Wadsworth.

[14] Slameto, Developing Critical Thinking Skills through School Teacher Training "Training and Development Personnel" Model and Their Determinants of Success. International Journal of Information and Education Technology, 4(2), 161-166, 2013

[15] Pachemska, T. \& Lazarova, L. K. (2016).Visualization of the Geometry Problems in Primary Math Education - Needs and Challenges -. Istraživanje Matematičkog Obrazovanja, 8(15), 33-37.

[16] Abdullah, N. \& Zakaria, E. (2014). VStops: A Thinking Strategy and Visual Representation Approach in Mathematical Word Problem Solving toward Enhancing STEM Literacy. Eurasia Journal of Mathematics, Science \& Technology Education, 10(3).

[17] Sutini, S., e.t.l, (2017). Identification of Critical Thinking Process in Solving Mathematic Problems. IOSR Journal of Research \& Method in Education (IOSRJRME), 07(04), 05-10.

[18] Van Garderen, D.(2006). Spatial visualization, visual imagery, and mathematical problem solving of students with varying abilities. Journal of Learning Disabilities, 39(6), 
496-506.

[19] Sa'dijah, C. (2019). Students' problem in communicating mathematical problem solving of Geometry. In IOP Conference Series: Earth and Environmental Science (Vol. 243, No. 1, p. 012128). IOP Publishing.
[20] Wegbreit, E., e.t.l. (2013). Visual Attention Modulates Insight Versus Analytic Solving of Verbal Problems. The Journal of Problem Solving, 4(2), 94-115.

[21] Sugiyono. (2014). Metode Penelitian Kuantitatif Kualitatif dan R \& D. Cetakan ke-11. Bandung: Alfabeta 